\title{
Sobre la inserción del arte activista argentino en los espacios de exhibición
}

\author{
On the integration of Argentinian activist art at \\ exhibition venues
}

\author{
DANIELA LUCENA \\ Universidad de Buenos Aires. \\ daniela.lucena@gmail.com
}

Recibido: 14 de enero de 2016

Aprobado: 18 de marzo de 2016

\begin{abstract}
Resumen
El trabajo se propone analizar la inserción institucional del arte activista argentino en los años posteriores a la crisis económica y social del 2001. Con este objetivo, se presenta primero una caracterización de los nuevos grupos de arte activista más significativos de la ciudad de Buenos Aires. Luego, se reconstruye su posición en el campo del arte a partir de las polémicas entabladas con el "arte light" de los 90 y las acusaciones cruzadas en torno a la "moda" del arte político. Por último, se examina la recepción de los grupos de arte activista en los espacios de exhibición porteños e internacionales y se reflexiona sobre la cuestión de la institucionalización de las prácticas estético-políticas.

Palabras clave: arte activista, estéticas políticas, instituciones artísticas.
\end{abstract}

Lucena, D. (2016): Sobre la inserción del arte activista argentino en los espacios de exhibición. Arte, Individuo y Sociedad, 28(3) 583-600

\begin{abstract}
This article examines the institutional integration of activist art in the aftermath of the 2001 economic crisis in Argentina. Following this aim, we begin with a description of the most significant new groups of activist art in the City of Buenos Aires. Then, we elaborate the position these new groups take up in the field with respect to their dispute with the "light art" from the $90 \mathrm{~s}$, and in relation to the mutual accusations over the "trend" of political art. Finally, we analyse the reception of these groups of activist art in art exhibitions in the City of Buenos Aires and abroad, and we reflect upon the institutionalization of these specific and situated aesthetic and political practices. Keywords: activist art, political aesthetics, artistic institutions.
\end{abstract}


Sumario: 1. Sobre los nuevos colectivos de arte activista, 2. El entramado de las polémicas, 2.1. "Arte light" de los 90: el gran enemigo cultural, 2.2. La moda del arte político, 3. El arte activista en los espacios de exhibición de Buenos Aires, 4. Reflexiones finales. Referencias.

Este artículo recoge resultados de la investigación "Producción y circulación de artes visuales en la post dictadura. Las relaciones del campo artístico con otras zonas del campo cultural de Buenos Aires (19832010), dirigida por Lucas Rubinich, financiada por la Universidad de Buenos Aires, subsidio UBACyT código 20020100101054 años 2011-2014.

\section{Sobre los nuevos colectivos de arte activista}

Luego de la crisis y el estallido social de diciembre de 2001 surgen en la escena pública nuevos colectivos de arte activista (Longoni, 2007) y adquieren una mayor visibilidad aquellos grupos surgidos desde mediados de los años 90. Se trata de colectivos de jóvenes artistas que trabajan en colaboración con las organizaciones piqueteras, los movimientos sociales y de derechos humanos e inscriben su práctica en el espacio urbano, en las asambleas vecinales, en las fábricas recuperadas, en las marchas y piquetes y también en espacios del circuito artístico.

Entre los grupos más significativos de Buenos Aires se destacan, por un lado, Etcétera... y el GAC (Grupo de Arte Callejero), cuyos inicios a mediados de los años 90 se encuentran fuertemente ligados a los escraches impulsados por el movimiento de HIJOS de detenidos y desaparecidos durante la última dictadura militar y, por otro, el TPS (Taller Popular de Serigrafía), surgido a partir de la revuelta de diciembre de 2001, en la Asamblea Popular de San Telmo ${ }^{1}$. Las acciones estético-políticas de estos colectivos de artistas son diversas, e incluyen la creación de la (contra) señalética urbana y la gráfica utilizada en los escraches a los represores impunes; la confección de placas para stencils; la realización de performances, muñecos y disfraces; la enseñanza de serigrafía; el estampado de remeras y banderas; la producción de afiches y el desarrollo de acciones carnavalescas en la calle (Longoni, 2005a).

La gran mayoría de sus integrantes son jóvenes artistas, con distintas trayectorias sociales, que ocupan en el campo artístico porteño el lugar de los recién llegados, con escaso capital simbólico específico. Si bien las formas en que cada colectivo concibe la práctica artística y los procedimientos y recursos estéticos que emplean en sus acciones y producciones son diversos, cabe destacar que no existe entre ellos una disputa estética de tipo formalista ni tampoco en relación con las metodologías más eficaces de intervención política. Estas discusiones, que sí han sido centrales en décadas pasadas entre grupos y artistas que planteaban su quehacer artístico ligado a la acción política -como por ejemplo los debates entre realismo y concretismo en la década del 40 o las tensiones entre vanguardia y revolución en los años 60-70-, no constituyen un rasgo característico del modo de inserción de estos jóvenes en el campo restringido de la producción artística.

¿De qué modo se delimita, entonces, la posición del nuevo arte político/activista en el campo artístico post 2001? ¿En relación con qué otros actores y estéticas se recorta su lugar diferencial en ese espacio jerarquizado de lucha? Para responder interrogantes resulta interesante reconstruir las posiciones expresadas por un conjunto 
de artistas y agentes del campo en el debate Arte Rosa Light y Arte Rosa Luxemburgo. El mismo tuvo lugar en mayo de 2003 en el Museo de Arte Latinoamericano de Buenos Aires (MALBA), museo de gestión privada inaugurado unos meses antes de la crisis del 2001 que rápidamente se convirtió en una de las instituciones más dinámicas y prestigiosas del campo artístico local.

\section{El entramado de las polémicas}

Como mercado lingüístico que supone una situación y un lenguaje legítimos, con interlocutores capaces de producir, evaluar y apreciar los discursos puestos en juego, el debate Arte Rosa Light y Arte Rosa Luxemburgo constituye una situación de intercambio privilegiada. Allí es posible observar la conformación de estrategias discursivas que dan cuenta de la relación objetiva entre sus competencias y permiten delimitar las posiciones que ocupan -o aspiran a ocupar- los distintos artistas y actores involucrados en la producción del valor social de las obras.

Resulta importante entonces considerar el debate del MALBA no como un hecho aislado, sino ponerlo en relación con otros dos episodios, sucedidos en el campo del arte porteño con anterioridad ese mismo año. Primero, la polémica desatada a partir del texto escrito por el crítico Ernesto Montequín (2003) para el catálogo de la muestra Subjetiva 1999-2002. Belleza y Felicidad en retrospectiva, curada por Emiliano Miliyo y llevada a cabo en la galería Belleza y Felicidad entre enero y marzo de 2003. Segundo, la muestra Ansia y Devoción realizada casi en simultáneo en la Fundación Proa, con la curaduría de Rodrigo Alonso, también autor del texto central del catálogo (Alonso \& González, 2003).

La conexión entre ambos textos es evidente, no sólo por sus opiniones coincidentes en la condena a un tipo de programa estético despolitizado surgido en los años 90 sino también por el hecho de que Alonso cita en su catálogo el todavía inédito escrito de Montequín (2003) para la muestra de Belleza y Felicidad. La posición que los autores sostienen antagoniza abiertamente con el arte light, mote generalizador y simplista con el que un prestigioso sector de la crítica denominó un disímil grupo de obras vinculadas al Centro Cultural Ricardo Rojas bajo la gestión de Jorge Gumier Maier entre 1989 y 1996.

El término light había sido enunciado por el crítico de arte del diario La Nación, Jorge López Anaya, en un artículo publicado en el periódico el 1 de agosto de 1992, a propósito de la muestra Gumier Maier-Laren-Londaibere - Schirilo en el Espacio Giesso. De a poco, aquel calificativo light que para los críticos era sinónimo de superficial, frívolo, lúdico, decadente, vulgar, decorativo, edulcorado, cosmético -entre otros adjetivos-, se convirtió en un mote que muchos de los artistas se apropiaron para recortar su posición en el campo del arte. Así, mientras que algunos reivindicaron esas propiedades atribuidas a lo light (como es el caso de Gumier Maier, Omar Schiliro o Marcelo Pombo), otros se distanciaron de ese término y los valores que conllevaba (por ejemplo Marcia Schvartz y Fernando Coco Bedoya). Para simplificar los términos de esta polarización, podría decirse que la posición defendida por Marcia Schvartz reivindicaba la tradición del pintor realista comprometido (que en Argentina hunde sus raíces ni más ni menos que en el prestigioso Antonio Berni), en tanto la de Gumier Maier se hallaba más cercana a la tradición romántica del l'art 
pour l'art (Cerviño, 2010). En esa oposición, la estética light fue leída en sintonía con los rasgos de la época posmoderna, caracterizada por su liviandad y su falta de compromiso político y social. Tiempo después, las jornadas ¿Al margen de toda duda? -organizadas en el Centro Cultural Rojas por Marcia Schvartz, Felipe Pino y Duilio Pierri en 1993- adhirieron el término rosa al adjetivo light con la intención de ligar este tipo de estética a la cultura gay, otro intento de descalificación que también fue reapropiado positivamente por muchos artistas del Rojas que habían tenido una fuerte participación en el activismo homosexual de los años 80 en Buenos Aires.

Ahora bien, según Montequín (2003) la estética del Rojas tendría una suerte de epígono en la Galería Belleza y Felicidad, creada por las artistas Fernanda Laguna y Cecilia Pavón en 1999. Esta galería había nacido como un espacio de exhibición por fuera del circuito comercial y rápidamente se convirtió en núcleo de reunión de una generación de jóvenes artistas emergentes que encontraron allí un espacio lúdico de sociabilidad y producción. Un nodo de las tecnologías de la amistad consistentes en "conectar y articular fragmentos de mundo, iniciativas de artistas en una vasta ecología cultural autárquica" (Krochmanly, 2010), en la que los artistas se conciben "como autoproductores de sí mismos: como sus propios directores, curadores, críticos, galeristas, escritores e investigadores" (Krochmalny, 2010). Belleza y Felicidad contó además, durante sus siete años vida, con la participación y el apoyo simbólico del artista plástico Roberto Jacoby, protagonista central de la vanguardia artística radicalizada de los años 60 , quien mantenía -y mantiene- una estrecha relación de amistad y producción con Laguna. Este no es un dato menor puesto que Jacoby, si bien poseedor de un importante y prestigioso capital artístico acumulado a partir de su posición como creador y referente del conceptualismo político latinoamericano, era acusado entonces de ser uno de los mentores del denostado arte light.

Volviendo al texto de Montequín (2003), la continuidad entre la estética del Rojas y la estética Belleza y Felicidad estaría dada por ciertos rasgos distintivos comunes, tales como el reinado de la subjetividad como valor absoluto y la repetida presencia de artistas consagrados como Roberto Jacoby o Gumier Maier como mentores y legitimantes de esos programas estéticos. La apatía política, la superficialidad, la valorización de la subjetividad, el conformismo de los artistas y la indiferencia ante la realidad fueron entonces las características que permitieron no sólo a estos autores sino también a varios otros actores del campo (críticos especializados argentinos y extranjeros, periodistas, artistas) asociar el arte light con el neoliberalismo de los 90, e incluso postularlo -reeditando la acotada interpretación del arte como espejo de la sociedad- como la expresión cultural del menemismo.

Más allá de que este tipo de definiciones reduccionistas en términos de filiaciones estéticas resultan insostenibles si se confrontan con las prácticas concretas de los actores y que los vínculos de los artistas comprometidos y los despolitizados del Rojas evidencian la imposibilidad de demarcar compartimentos cerrados (Amigo, 2008), el del arte light resulta un discurso ineludible a la hora de comprender las estrategias que los distintos agentes del campo movilizaron para conformar o sostener su espacio. Es por esto que, tal como se ha señalado, resulta importante inscribir el debate Arte Rosa Light y Arte Rosa Luxemburgo en el marco de las disputas simbólicas que se generaron en torno a esa denominación. 


\section{1. "Arte light" de los 90: el gran enemigo cultural}

"Ese debate [Arte Rosa Light y Arte Rosa Luxemburgo] lo promoví en el 2003 cuando advertí que había una parva de interesados en enfrentar la galería Belleza y Felicidad y al proyecto Venus con el arte activista", dice Roberto Jacoby (2008, p. 44). Organizado por el Proyecto Venus -microsociedad autogestionada de artistas impulsada por Roberto Jacoby entre 2002 y 2006- ya desde la elección del título del encuentro puede entreverse la posición sostenida por Jacoby con respecto las disputas por el legítimo arte político. Con la elección de otro estereotipo tan reductor y polémico como Rosa Luxemburgo unido por la conjunción y al mote Rosa Light, Jacoby buscaba burlarse de lo que él consideraba un falso antagonismo entre un supuesto arte político y otro apolítico. Un enfrentamiento que -como vimos- remitía a las polémicas entre los pintores de los años 80 y ciertos artistas del círculo del Centro Cultural Rojas, pero que se reeditaba en los años de la poscrisis sumando nuevos protagonistas: la joven generación de artistas activistas. La tarjeta de la invitación reforzaba esta idea, mostrando juntos dos potes de temperas rosa que, si bien tenían leves diferencias, se veían muy similares. Posteriormente, Jacoby explicaba: "Era una manera de señalar que no había que plantear una disyunción. [...] Una ironía acerca del eje de discusión, de las pretensiones 'revolucionarias' de algunos operadores y respecto del "narcisismo de las pequeñas diferencias"' (2003a, p. 387). El desarrollo de las exposiciones de los invitados a la mesa y el posterior intercambio con los asistentes mostrarían, sin embargo, que la mayoría de los participantes había leído el provocador título de la invitación como una oposición que reforzaba el antagonismo entre ambas denominaciones. Rosa Light y Rosa Luxemburgo expresaban varios pares de opuestos que claramente excedían las cuestiones estrictamente formales o estilísticas de las obras: liviano vs. pesado, cultura popular vs. alta cultura, mal gusto vs. buen gusto, internacional vs. nacional, alegre vs. serio, descomprometido vs. comprometido, posmoderno vs. moderno fueron algunos de los significados que muchos artistas, gestores, críticos e incluso buena parte del público contrapusieron ese día, dejando en claro que con todas esas cualidades banales lo light nunca podría reclamar ser un arte político.

Asimismo, un repaso por los expositores y el público participante hace posible anticipar la intensidad que alcanzaría el debate. El panel estaba conformado por las investigadoras Ana Longoni y Andrea Giunta (autoras de los estudios más relevantes sobre el arte de los años 60 en Argentina), Ernesto Montequín, Roberto Jacoby y Magdalena Jitrik (artista plástica cuya obra había sido expuesta tanto en la Galería del Rojas como en la muestra Ansia y Devoción y que desde el 2001 formaba parte del colectivo de arte activista TPS). Oficiaba como coordinador del mismo Gustavo Bruzzone (coleccionista del denostado arte light y editor fundador de la revista ramona motorizada por Roberto Jacoby). Entre el público -que sumaba unas 350 personas aproximadamente- se encontraban críticos, investigadores, artistas y galeristas de diversas tendencias estéticas y procedencias institucionales (entre ellos Florencia Braga Menéndez, Sebastián Gordín, Iván Calmet, Martín Kovensky, Laura Malosetti Costa, Roberto Amigo, miembros del Centro Cultural Azucena Villaflor de Avellaneda, Cristian Dios, Ana María Battistozzi, Santiago García Navarro, Nora 
Dobarro, Eduardo Molinari, Cristina Schiavi e integrantes de los grupos GAC y Etcétera, entre muchos otros).

Para sintetizar lo ocurrido en el auditorio del Malba, puede señalarse que las intervenciones giraron en torno a la clásica dicotomía entre "el arte por el arte" y "el arte social", el controversial tópico del vínculo de los artistas con las instituciones y la recurrente tensión entre política y autonomía o libertad artística. Así, la vuelta a la contienda que opone el arte puro/formalista al arte comprometido socialmente -tema que se reedita cíclicamente en Buenos Aires desde la década del 20 del SXXy la reiterada pregunta por la supuesta liviandad y apatía política del arte argentino de los 90 se convirtieron en los dos grandes ejes de reflexión en el Malba. Algo interesante para destacar sobre el debate es que la discusión más acalorada ocurrió con los miembros del público y no entre quienes compartían el panel de expositores.

En lo referente a éste análisis, interesa señalar dos momentos particulares del intercambio, que son centrales para comprender la nueva posición del arte políticoactivista. El primero se vincula con la intervención de Federico Zukerfeld, miembro del colectivo Etcétera. El artista leyó un apartado del texto Bisagra Times (2003) titulado Fealdad y Tristeza, escrito al estilo del clásico manifiesto de la vanguardia histórica. Allí, Zukerfeld comenzaba describiendo la contradicción del sistema simbólico dominante en relación con la realidad de la época y la consiguiente apertura a un nuevo orden de representaciones. Luego, se refería al arte de los años 90 enfatizando la exacerbación del individualismo, la falta de compromiso colectivo y la despolitización que lo caracterizaron. En ese mismo sentido, hacía un llamado de atención a los presentes, desenmascarando la verdadera esencia del arte light que fue, según el artista mucho más que una tendencia estética:

No seamos ingenuos. Fue la objetivación de todo un sistema de pensamiento. Fue la imposición de un aparato vaciador de contenidos. Una trampa muy bien diseñada, donde el arte funciona como un aliado del consumo, como un elemento identificador, y que por lo tanto, es utilizado y manipulado por las terminales ideológicas de poder para poder percibir sus objetivos (Zukerfled, 2003, p. 15).

Por último, anunciaba la llegada de una nueva época histórica donde "daremos un giro nuevamente en la relación entre el arte y la sociedad" (Zukerfeld, 2003, p. 15).

De este modo, se hace visible en las palabras de Zukerfeld la presencia permanente del pasado específico del campo, recordado a partir de un gesto de ruptura que lo invocaba para conformarse como tal. A partir de la impugnación de quién se erigía como el portavoz de una nueva época artística, el denominado arte light de los 90 volvía a estar en el centro de la escena, esta vez a partir de la evocación de una nueva generación de artistas activistas que lo utilizaba para diferenciarse y recortar así su posición en el campo ${ }^{2}$. Tal como lo advierte una crónica periodística de la época, en el contexto de poscrisis el arte light de los 90 aparecía como el gran enemigo cultural para muchos artistas y productores culturales. 


\subsection{La moda del arte político}

El segundo momento que quisiera reponer se refiere a la intervención de Roberto Jacoby (2003b, p. 70) y sus reflexiones sobre lo político en el arte y el vínculo de los artistas con las instituciones. Con respecto a la relación de los artistas con la institución, debo señalar que este tópico era (y es), sin dudas, uno de los grandes interrogantes que una y otra vez aparecen en las reflexiones de académicos y artistas -sobre todo quienes proponen una práctica estético-política-. Como ha señalado la investigadora Andrea Giunta, tal vez esto se deba a la gran limitación conceptual que generó el libro de Peter Bürger, Teoría de la vanguardia (1987). En la década del 80 , fueron muchos los estudios que basaron su análisis de las vanguardias argentinas y latinoamericanas en la conceptualización de Bürger y, a partir de allí, "fue difícil pensar otra forma de vanguardia cuyo eje no se centrase en el anti-institucionalismo" (Giunta, 2003, p. 9). Por otra parte, los usos de término vanguardia, que en su origen aparecen íntimamente ligados a la política (sobre todo de izquierda) generan su constante ligazón con el campo político y las adhesiones partidarias.

No es de extrañar, entonces, que Jacoby traiga a un debate donde se discutía sobre lo político o no político en el arte el tan conflictivo tema de las relación con la institución ¿Qué aspectos de ese vínculo entre los grupos y artistas con los espacios de exhibición y los organismos que apoyan la actividad artística decidió remarcar el artista en el MALBA? Provocativamente, hizo alusión a "algunas instituciones internacionales apoyan exclusivamente proyectos socio-artísticos que parecieran tener a la experiencia de Tucumán Arde como manual de instrucciones, como formulario de inscripción para pedir el apoyo institucional" (2003b, p. 70).

La referencia a Tucumán Arde -esa experiencia crucial de la vanguardia argentina de los años 60 que lo contó entre uno de sus protagonistas centrales- juega un rol simbólico importante en el marco del debate. Por un lado, porque ubica a esa acción colectiva como una referencia ineludible para el quehacer del arte político, al mismo tiempo que deja entrever cierta desconfianza hacia la pretendida originalidad de las nuevas prácticas estético-políticas. Por otro, porque refuerza su legitimidad como actor del campo: una legitimidad que era insistentemente puesta en tela de juicio por los detractores del arte light y que era necesario apuntalar.

Desde ese lugar, Jacoby alertaba sobre los peligros de un poder ajeno a los artistas que dictara el tipo de obras que deben producirse para formar parte del circuito globalizado del arte. Defendía, de este modo, la autonomía artística frente a los requerimientos de los espacios de exhibición y las instituciones financiadoras internacionales, tomando como ejemplo el accionar de curadores extranjeros que recomendaban a los artistas argentinos radicalizar su arte y descartaban obras que, según sus criterios, no eran lo suficientemente políticas:

Un curador que vino a realizar una muestra internacional recomendó a grupos y artistas individuales - que vienen trabajando desde hace años en la Argentina-politizar su arte, puesto que para el curador el arte de ellos no era suficientemente político. De hecho, muchos de estos artistas no fueron ni siquiera invitados a conversar con este curador, quien a pesar de tener un conocimiento bastante somero de la historia argentina, se considera con derecho de determinar la radicalidad o establecer un indice de radicalidad política del arte en la Argentina (2003, p.70). 
Aunque no de modo explícito, su comentario hacía referencia al Proyecto ExArgentina, una investigación conjunta entre artistas e intelectuales (sobre las que volveremos más adelante), acerca de la crisis Argentina y el impacto de la aplicación indiscriminada de políticas neoliberales, que se proponía conferir visibilidad artística a contextos dominados por el economicismo. Impulsado por el Goethe-Institut Buenos Aires y financiado por la Kulturstiftung des Bundes (Fundación Federal Alemana de Cultura), el proyecto se extendió a lo largo de cuatro años e incluyó la realización de coloquios, publicaciones y muestras en Colonia (Alemania), Barcelona (España), Miami (USA) y Buenos Aires (Argentina), todas bajo la curaduría artística de Alice Creischer y Andreas Siekmann. Entre los artistas argentinos participantes se encontraban, entre otros, los colectivos de arte político-activista GAC y Etcétera.

Aunque indirecto, pero dirigido a aquellos receptores capaces de captarlo, el comentario de Jacoby sobre ciertas imposiciones curatoriales internacionales no tardó en surtir efecto. Desde el público, uno de los miembros del GAC (Federico Geller) defendió su participación en el proyecto Ex Argentina, celebrando la invitación y el hecho de que esos subsidios del Estado alemán sean destinados al arte político. Se refirió también a las tensiones internas generadas en su grupo a partir de la decisión de participar en la Bienal de Venecia, a la que el GAC había sido recientemente invitado por el reconocido curador Carlos Basualdo. Por último, desestimó la existencia de una supuesta moda del arte político que muchos -al igual que Jacobyveían materializarse en ese tipo de invitaciones. Su posición divergente con respecto a las instituciones quedó sintetizada al final de su intervención: "el mejor modo es multiplicar experiencias, participando del mundo del arte como modo de anular estructuras de jerarquías" (En Ramona, 2003, p. 70).

En cuanto al arte político, desde su perspectiva, "la formación de enlaces de confianza, de amistad, de donación, de intercambio, de afinidad" constituye "el fenómeno más genuinamente político que se está produciendo en el ambiente artístico argentino en los últimos años". Revalorizando así la politicidad de sus últimas iniciativas (el Proyecto Venus, Bola de Nieve, Chacra99, la revista ramona, la Zona Temporalmente Autónoma, entre otras), el artista marcaba su distancia con las propuestas de los nuevos colectivos de arte-activista y enfatizaba la relación entre arte y política ligada a "su carácter instituyente de espacios sociales experimentales" (Jacoby, 2003b, p. 70).

Hasta aquí, la recuperación de estas instancias del debate permite comprender el modo de construcción de la posición del arte político-activista en el contexto de la poscrisis. La existencia de esta nueva posición puede corroborarse a partir del hecho de que el accionar de la nueva generación de artistas políticos plantea "problemas" que son analizados y discutidos por otros actores legítimos del campo. Sin embargo, su disponibilidad se vincula no solo con las luchas de poder propias del campo artístico (arte light vs arte político / institucionalización vs. libertad de creación), sino también con factores coyunturales externos, tales como las múltiples movilizaciones y reclamos populares surgidos a partir del estallido de la crisis en diciembre de 2001. Fue justamente esa convulsionada escena social la que otorgó mayor visibilidad a los colectivos de arte político-activista surgidos en los años 90 y motivó el surgimiento de otros nuevos grupos. 
Asimismo, la existencia de una tendencia curatorial internacional que, en el contexto de poscrisis, dirigió su mirada a las producciones del arte político-activista y lo instaló en las agendas de los más prestigiosos eventos artísticos internacionales, resultó un factor legitimante de gran peso en la construcción y la consolidación de esa nueva posición. De hecho, más allá de los argumentos esgrimidos a favor o en contra de la moda del arte político por los distintos actores, es notable la participación de los colectivos de arte político-activista en distintos espacios de exhibición del circuito artístico internacional entre los años 2002 y $2007^{3}$.

En ese período, el colectivo Etcétera... -devenido Internacional Errorista a partir de noviembre de 2005- expuso sus producciones en Ex Argentina, Museo Ludwig de Colonia (Alemania, 2004), en el Forum Stadtpark (Austria, 2004), en el MEIAC y en el MACBA (España, 2004), en las muestras Collective Creat ivity de Kassel (Alemania, 2005) y To eat to create (Croacia, 2005), en la conferencia El arte puede ser hecho por todos (Barcelona, 2005), en la Bienal de Venecia (2005), en la Nuova Universidad de Bellas Artes de Milano (2006), en el Center for Contemporary Art de Moscú (2006), en Mori Gallery (Sydney, 2007), en Longwood Art Gallery (Nueva York, 2007), en el Van Abbemuseum (Holanda, 2007) y en el encuentro Tránsitory Público (Los Ángeles, 2007).

El GAC, por su parte, mostró sus trabajos en la muestra Colectivos y Asociados (Madrid, 2002), en la 50 Bienal de Venecia (2003), en The Echo Show (Escocia, 2003), en Ex Argentina, Museo Ludwig de Colonia (Alemania, 2004), en la muestra Collective Creativity de Kassel (Alemania, 2005), en el MACBA (2005) y participó en los encuentros Zona de acción (San Pablo, 2004) y Klartext (Berlín, 2005).

Por último, el TPS expuso en el Foro Social Mundial Bombay (India, 2004), en el Centro Colombo Americano de Medellín (2004), en Collective Creativity de Kassel (Alemania, 2005), en el San Diego Museum of Art (2005), en el Centre d'art contemporain de Montbéliard (Francia, 2006), en la $27^{\circ}$ Bienal de San Pablo (2006), en Zoo Art Fair (Londres, 2006), en la II Bienal de Arte Contemporáneo de Moscú (2007), en el Museo de Arte Contemporáneo de Río de Janeiro (2007) y en la Bienal de Valencia (2007).

A partir de esta situación de alta visibilidad en el circuito internacional, diversas reflexiones han problematizado la tendencia hacia la institucionalización o legitimación del arte político y las consiguientes problemáticas que esto plantea a las producciones artísticas latinoamericanas. En este sentido, la teórica chilena Nelly Richard se ha referido a un creciente proceso de antropologización y sociologización del arte latinoamericano en el contexto del mundo global y el auge de los discursos del multiculturalismo, en el que las instituciones culturales de los centros urbanos llaman a los grupos marginales o subalternos a recurrir al arte para denunciar y visibilizar sus condiciones de vida y sus demandas. Para el arte de América Latina, este proceso implica "que la mirada internacional de su condición periférica que no compita con el centro en artificios discursivos ni complejidades retóricas sino, más bien, que ilustre 'su compromiso con la realidad' enfatizando una mayor referencialidad de contexto" (Richard, 2007, p. 79).

El investigador Adrián Gorelik también ha llamado la atención sobre este fenómeno, destacando el renovado interés de la crítica internacional por el arte de las 
regiones periféricas desde mediados de los 90, condenadas a "pagar en la moneda del compromiso social y político su derecho a existir en el mundo del arte globalizado" (Gorelik, 2005, p. 6). En el caso del arte argentino, luego de la crisis del 2001, se produjo una rearticulación de las formas y los contenidos a través de la irrupción de "una realidad de miseria, cartoneros, fábricas tomadas y piquetes" (Gorelik, 2005, p.7) que fue realimentada por el circuito internacional y sus demandas. La política, según este autor, ha sido internalizada por el arte como una variable más de sus procedimientos y su lógica institucional y "sin embargo, la relación entre arte y política se sigue enunciando como si nada hubiera cambiado" (Gorelik, 2005, p. 8). Ana Longoni, por su parte, no solo reflexiona sobre la tendencia hacia la institucionalización de las prácticas estético-políticas que se nutre de artistas y colectivos que fusionan su trabajo con movimientos sociales o activismos anti-globalización, sino que también repara en la incomodidad que provoca en muchos de estos grupos "la súbita avidez de curadores, críticos y espacios institucionales (muchos de ellos, históricamente reactivos a cualquier manifestación artística que pusiera en cuestión su status de autonomía o pretendiera una relación crítica en su entorno)" (Longoni, 2005b, p. 62). En este sentido, muchos de los propios artistas activistas han dado a conocer sus experiencias, conflictos y balances a partir del ingreso de sus producciones en las vidrieras más notorias del arte internacional.

Para ilustrar estos dilemas, considero oportuno recuperar el balance del antes mencionado Proyecto Ex Argentina que propuso Longoni a quienes habían estado involucrados en esa experiencia, y que fue publicado en la revista Ramona de abril del 2006. En la introducción de esa iniciativa, Longoni da a conocer uno de los objetivos que la impulsan a generar esa reflexión entre los artistas, investigadores y gestores participantes: "encarar un balance de Ex Argentina podría ayudar a pensar acerca de la deriva de las tensiones entre arte y política, historia y presente, el lugar de la política en el arte, el del arte en la política, sus mutuas reformulaciones y corrimientos" (En Ramona, 2006, p. 57). De todas las intervenciones publicadas voy a extraer tres comentarios que nos conducen directamente a las complejidades y contradicciones que generó la inserción del activista en prestigiosos espacios internacionales de exhibición. Los miembros de Etcétera disparan una inquietante pregunta: "Ahora que 'somos exportadores' de Protestas, Escraches, Piquetes, Luchas Sociales y Fábricas Recuperadas... ¿Seguimos Ardiendo? Es la sensación de un interrogante del tamaño de la Luna..." (En Ramona, 2006, p. 68). Carolina Golder, miembro del GAC, desarrolla una extensa reflexión en primera persona, en la que lamenta todo lo que el proyecto podría haber generado y no lo logró:

Quizá deberíamos hablar de fracaso sobre todo en cuanto a las relaciones humanas entre los que participamos del proyecto, fracaso que se hizo evidente en la muestra en Colonia, en los pocos lazos que se entretejieron entre los participantes, en las pocas discusiones y debates, en el poder de las Instituciones y sus evidencias más concretas en cuanto al predominio de la individualidad artística de los sujetos. También se puede pensar en términos de fracaso porque sólo quedó expuesto en el museo lo espectacular, y el predominio del concepto de "obra mostrable en un museo" se tragó toda la dimensión procesual del proyecto. Ex Argentina pudo haber sido pero no fue un espacio que sirviese para abrir, reflexionar, pensar y proponer ciertas lógicas por fuera del 
sistema hegemónico de poder. Un espacio en el cual se armasen redes, un lugar en el cual compartir similitudes, semejanzas, diferencias, modalidades y metodologías de las distintas experiencias tanto de los grupos como de los artistas de la Argentina y de otros países. Un lugar en donde poder plantear interrogantes, llegar a distinguir los cruces que se producen en la trama cultural: entre el arte y la política, entre la militancia y el arte, así como compartir con otros la determinación de investigar y crear nuevas prácticas que apunten a la transformación de la realidad y sus representaciones. Creo que en esos sentidos puede hablarse de un fracaso. Del sabor de lo que pudo haber sido y no fue (En Ramona, 2006, p. 71).

Por último, la propia Ana Longoni, miembro de una comisión de investigación ad hoc del proyecto dedicada a trabajar sobre el archivo de Tucumán Arde describe así su experiencia en la muestra de Colonia:

“... terminé siendo parte del contingente de argentinos que viajamos para colaborar con el montaje de la muestra en Colonia. Allí pudimos sentir en carne propia las distancias insalvables entre las prácticas de intervención callejeras y su ingreso a la institución artística, mucho más tratándose de semejante museo en un entorno que nos dejaba 'fuera de contexto'. No se trata de que hubiésemos sido ingenuos u oportunistas al aceptar participar del proyecto (o quizá sí, pero no solamente), sino que una cuestión de escala escapaba completamente no sólo a nuestra decisión sino incluso a nuestra vista. Quizá el momento en que se evidenció con mayor crudeza esta distorsión fue el de la inauguración de la muestra. Luego de dos semanas de montaje, los veinte argentinos allí presentes, sin traductor ni invitación a tomar la palabra, quedamos excluidos literal y simbólicamente del acto, fuera del discurso, mientras distintos conferenciantes debatieron en alemán acerca de cómo Ex Argentina se inscribía en los asuntos de la política cultural germana. Fue para mí inevitable la sensación de estar siendo parte del mobiliario exótico del lujoso museo, sin por ello poner en duda las mejores intenciones de los organizadores de la exposición (En Ramona, 2006, p. 72).

A continuación, reflexiona sobre el ingreso de ciertas prácticas activistas que, nacidas en la calle o en los espacios de los movimientos de derechos humanos y sociales, de pronto se veían expuestas en la institución, perdiendo todo rastro de la potencia y la vitalidad que habían tenido en el afuera:

“... los registros de acciones callejeras (en video, fotos, afiches) llegaban a traslucir muy poco del impacto que provocaron en su origen. El ingreso al museo congelaba en un documento lo que minutos antes había sido acción. Reponer un contexto tan específico como el de los escraches a represores o el de las revueltas de diciembre de 2001 resultaba una tarea ímproba. Al mismo tiempo, los grupos argentinos que se propusieron realizar acotadas acciones callejeras en la próspera Colonia se encontraron con barreras culturales dificiles de trasponer (En Ramona, 2006, p. 73).

Su reflexión culminaba con los intercambios que, a raíz de este balance, había mantenido con los españoles Marcelo Expósito y Jorge Ribalta. La cuestión de la eficacia adquiría entonces un nuevo matiz, no ya pensada en términos de intervención política en el espacio de la calle, sino al interior del museo, la feria o la galería de arte. Diseñar formatos o dispositivos que presenten y formalicen los resultados 
del trabajo de archivo e investigación de modo que se reactiven productivamente esas experiencias, era entonces uno de los desafíos ineludibles a encarar. En ese proceso, no podían dejarse de lado las especificidades de cada espacio, sus reglas, sus públicos y sus potencialidades. En definitiva, lo que el balance dejaba como saldo, era la necesidad de pensar el vínculo con la institución en cada coyuntura específica. Decirle si o no al museo no era algo que podía definirse de una vez y para siempre. Cada situación expositiva, cada proyecto de investigación y cada propuesta curatorial merecían analizarse en contexto, sin perder de vista los intereses en juego, los discursos puestos en marcha y las estrategias susceptibles de ser desplegadas.

Mientras tanto ¿qué ocurría con estos grupos en los espacios de exhibición de la ciudad de Buenos Aires? ¿Cómo fue la recepción de las obras de los nuevos grupos de arte activista en el circuito artístico porteño? ¿Cuál fue su espacio institucional de circulación?

\section{El arte activista en los espacios de exhibición de Buenos Aires}

Un buen punto de partida para abordar estos interrogantes puede ser la recopilación de las muestras realizadas por estos grupos en la Ciudad de Buenos durante el mismo período 2002-2007 y el análisis del tipo de espacio de exhibición dónde fueron realizadas.

TPS su primera muestra Un año en el 2002, en la ya mencionada Galería Belleza y Felicidad. Al año siguiente expuso Territorio Urbano / Situaciones Proyectos en el Centro Cultural La Casona de los Olivera, espacio abierto en el año 2000 donde se exhiben todo tipo de expresiones artísticas. El Centro, que cuenta con el apoyo del Ministerio de Cultura de la Ciudad para el mantenimiento edilicio y los salarios de sus 40 empleados, no comercializa obras y tampoco participa en ferias nacionales o internacionales. Además, son los propios artistas quienes financian el montaje de las muestras que realizan. En 2005 formó parte de la exposición colectiva Artistas plásticos por Kosteki y Santillán, realizada en la Sala Nacional de Exposiciones Palais de Glace y en 2006 de la muestra Adquisiciones, donaciones y comodatos del Malba.

En relación con el GAC y Etcétera, debe señalarse la realización de la tercera etapa del proyecto Ex Argentina en 2006, que culminó en Buenos Aires con una muestra en el Palais de Glace y una serie de encuentros y debates en FM La tribu, la Imprenta Chilavert Artes Gráficas, el local de H.I.J.O.S y el Hotel Bauen. En el marco de esas actividades, las salas oficiales del Palais de Galce se plantearon como el nodo desde el cual partían las líneas "que guían hacia espacios independientes, que por su activa participación en los procesos sociales durante los últimos años resultan fundamentales en la constitución de esta red que une prácticas artísticas y políticas". Allí expuso sus trabajos el grupo Etcétera pero, a diferencia de lo ocurrido en la muestra anterior del proyecto (en el Museo Ludwig de Colonia, Alemania, 2004), el GAC no participó como grupo debido a ciertas tensiones suscitadas con los curadores alemanes y finalmente solo se presentó a la muestra una de sus integrantes de modo individual.

El grupo Etcétera..., además, expuso en el año 2003 una serie de afiches, fotografías, volantes y objetos utilizados o realizados en el marco de sus acciones artísticas callejeras en la Sala Clément Moreau del Centro de Documentación e 
Investigación de la Cultura de Izquierdas. El espacio, si bien mostró en algunas ocasiones producciones artísticas contemporáneas vinculadas con la política, se enfoca más en las exposiciones históricas que se nutren de su propio acervo documental. Sus objetivos y prioridades -la recuperación y visibilización de afiches, gráfica, fotografias e ilustraciones de las organizaciones, partidos y movimientos de izquierdas desde 1890 hasta la actualidad- lo ubican al margen del circuito de venta de obra de la Ciudad de Buenos Aires.

En el año 2004, Etcétera... presentó un registro de la acción ArteBIENE en la galería Arcimboldo. Este espacio de gestión privada, creado en 1995 y dirigido desde entonces por Pelusa Borthwick, es el único que cuenta con un gabinete específico dedicado al arte político. Allí han expuesto -y exponen- sus trabajos tanto los artistas más reconocidos por la crítica y el público, como otros de menor trayectoria o que recién comienzan su camino en el mundo del arte. Por último, en al año 2007, el grupo festejó sus diez años de vida con una exposición retrospectiva ETCÉTERA... ETCÉTERA... Exposición antológica 1997 al 2007 en el Centro Cultural Recoleta. Allí, una línea cronológica guiaba al espectador a lo largo de sus intervenciones y producciones, registradas a través de textos e imágenes que narraban la trayectoria del grupo.

Con respecto a ArteBIENE, se trata de una acción que merece una mención aparte, en tanto su realización pone en escena la indiferencia de los galeristas ante el arte activista y el conflicto de buena parte de estos jóvenes artistas con las instituciones, el mercado y la lógica dominante del campo artístico en general. Organizada por el grupo Etcétera, la primera "edición" de ArteBIENE se realizó en 1999, en las puertas de la mega-feria ArteBA y consistió en la exposición colectiva de obras bajo el reclamo de una "mayor apertura y pluralidad del campo cultural" (Etcétera, 2007). $\mathrm{Al}$ año siguiente, la crítica al modo de funcionamiento del campo continuó con un cuestionamiento específico al mercado de obras de arte y la sociedad de consumo: una contraferia con stand propio, música y champagne confundía al público que asistía a la feria mientras los jóvenes artistas, vestidos de gala y escoltados por un policía de la Federal, repartían folletos donde daban a conocer sus críticas.

En el 2001, la acción de Etcétera se trasladó con una performance al interior mismo de ArteBA. Ante la inminente devaluación de la moneda argentina los artistas imprimieron miles de billetes falsos de 100 dólares, cuyo reverso indicaba 00 pesos argentinos. Con ese dinero y vestidos como empresarios adinerados con maletines negros, los artistas dejaban caer dinero y ofrecían a los galeristas comprar las obras más costosas del la feria.

Dos años más tarde, en 2003, siguiendo el leitmotiv de Arte BA "Los artistas se anticipan al futuro" Etcétera presentó el proyecto ArteBIENE 2004 donde proponían la redistribución del espacio público frente a La Rural (donde se realiza ArteBA) con el fin de realizar una exposición colectiva e independiente. En apoyo al proyecto se recolectaron firmas de muchos artistas, críticos, galeristas, asistentes a la feria y vendedores ambulantes. De ese modo, las planillas con las firmas conformaron una "obra de arte" que apoyaba un proyecto fantasma: "Si en el arte lo que vale es la firma, ¿cuantovalentodasjuntas?" preguntaban irónicamente los miembros de Etcétera (2007). 
De este modo, la feria de arte contemporáneo más importante y concurrida del país se convertía en el espacio privilegiado por los jóvenes artistas para realizar acciones y perfomances críticas, ante la lógica hegemónica del circuito artístico local. Esta situación, si bien se modificó levemente con la incorporación de algunas pocas obras de arte activista en ciertos espacios de exhibición porteños, es la que predominó y predomina incluso hasta el día de hoy.

\section{Reflexiones finales}

Recapitulando lo dicho hasta aquí, puede observarse que durante el período analizado es notablemente menor la cantidad de muestras realizadas por los tres grupos en la Ciudad de Buenos Aires, en relación con la alta participación de estos colectivos en el circuito internacional. Mientras que el GAC expuso sus trabajos en ocho eventos artísticos realizados fuera del país, en Buenos Aires no mostró sus producciones en ningún espacio institucional del campo artístico. Con respecto al TPS y Etcétera..., si bien fueron los que más exposiciones registran en los espacios de exhibición de Buenos Aires, ambos grupos realizaron más del doble de muestras en el exterior que en el país durante esos años. Debe agregarse, asimismo, que los grupos de arte activista tampoco fueron invitados a la II Bienal de Buenos Aires (2002) ni a la Bienal del Fin del Mundo (2007), las dos únicas exposiciones de este tipo llevadas a cabo en el país durante esos años.

Para comprender cabalmente esta información, resulta importante destacar que durante los años comprendidos entre 2002 y 2007 se registra un período de expansión del sistema institucional y mercantil del arte argentino. Tal vez por su menor sensibilidad a las crisis político-económicas o por ser considerablemente más estable que la bolsa, el mercado artístico argentino registró en la década del 2000 un notorio crecimiento sostenido. "En 2002, cuando el país se incendiaba, la inversión en arte creció", sostiene Julio Abal, jefe del Departamento de Arte del Banco Ciudad en un informe publicado por el suplemento iEco del diario Clarín, el 28 de agosto de 2011. En esa misma nota se informa que ese crecimiento se mantuvo durante toda la década hasta llegar a un volumen cercano a los 30 millones de dólares anuales.

A su vez, es posible comprobar durante toda la década una importante ampliación del circuito de galerías y museos, tanto en el ámbito público como privado. De los 240 espacios de exhibición hasta el momento relevados, más de la mitad (139) fueron abiertos en la década del 2000; de esas 139 aperturas, 85 se concentran en el período especifico 2002-2007 aquí analizado.

Es decir que, a pesar de la multiplicación durante toda la década del 2000 de espacios de exhibición -que van desde el Malba hasta pequeñas iniciativas autogestionadas de artistas- el arte activista no tuvo una presencia relevante en el circuito de exhibición y venta porteño: de los 56 espacios dedicados al arte emergente (obras de los años 80 en adelante), sólo 5 mostraron las producciones de estos colectivos.

Así, mientras sus trabajos lograban una vasta circulación en las bienales y museos más prestigiosos del circuito internacional, en Buenos Aires las acciones y muestras más significativas de estos grupos fueron aquellas que se llevaron adelante en la calle, por fuera (e incluso en contra) de los espacios institucionales del campo del arte: 
el Mierdazo en el Congreso Nacional (Etcétera); Arte y Confección (GAC, TPS y Etcétera en la fábrica textil recuperada Brukman); Desalojarte en progresión (GAC en el Centro Cultural San Martín), Ceramicazo (Etcétera y TPS en el festival organizado por los trabajadores de la fábrica recuperada Zanon), Mural de Afiches en Estación Darío y Maxi (TPS en la estación Avellaneda del Ferrocarril Roca), Lationamérica Arde (TPS en el Centro Rosa Luxemburgo ligado al Partido de los Trabajadores Socialistas), La Internacional Errorista (Etcétera en la Cumbre de las Américas, Mar del Plata) y ArteBIENE (Etcétera en ArteBA), entre muchas otras.

De este modo, puede observarse que la alta participación de los nuevos colectivos de arte activista en bienales, exposiciones, talleres y otros espacios legitimados del circuito artístico internacional fue significativamente menor en los espacios de exhibición porteños. En años donde proliferaron de un modo inédito nuevos espacios de exhibición y circulación dedicados fundamentalmente al arte argentino contemporáneo y emergente, las prácticas estético-políticas del arte activista no fueron privilegiadas en la gran mayoría de las selecciones realizadas por los galeristas y curadores del circuito local.

La cuestión de la institucionalización, tema que desde las primeras rupturas vanguardistas del siglo XX constituye un problema ineludible para el arte político, debe comprenderse como un tópico que circula entre los actores del campo y que determinadas coyunturas hacen que se reedite con más fuerza, pero que responde fundamentalmente a la autoreferencialidad del campo artístico. Quiero decir: en los años posteriores a la crisis del 2001, las discusiones en torno a este tema fueron tan potentes y resonantes no solo por la existencia de una mirada curatorial globalizada que exhibía las prácticas callejeras en los espacios más significativos del arte internacional, sino porque fue la institucionalización el tópico que marcó el parteaguas entre el nuevo arte activista y el arte político revolucionario de los años 60 , "ese pasado de extraordinaria vitalidad que es difícil no reivindicar de uno u otro modo" (Rubinich, 2009, p. 114).

De hecho, la muestra más resonante de arte político del período fue "Arte y política en los 60", curada por Alberto Giudici. Bajo el patrocinio de la Fundación Banco Ciudad, la exposición realizada en el Palais de Glace en el año 2002 reunió las obras de los protagonistas más destacados de la vanguardia radicalizada de los 60 (Renzi, Vigo, Bony, Carpani, Dowek, Jacoby, Paksa, Greco y Grippo entre varios más) y logró no solo una muy favorable recepción entre críticos y artistas sino también un gran éxito entre el gran público, que concurrió masivamente a visitar la muestra. Tiempo después, el escándalo por la censura motorizada por el actual Papa Francisco -entonces cardenal Bergoglio de la Ciudad de Buenos Aires- sobre la obra del artista León Ferrari constituyó acaso el punto cumbre de las reflexiones sobre el encuentro entre vanguardias estéticas y políticas argentinas. Con la clausura de la muestra retrospectiva de León Ferrari en el Centro Cultural Recoleta, a causa de su obra de 1965 La civilización occidental y cristiana, el arte político de los 60 volvía con toda su potencia revulsiva a ocupar el centro de la escena, movilizando no solo manifestantes que marcharon en favor o en contra de la censura, sino también debates políticos y estéticos sobre la eficacia del arte, el rol del Estado, las fuentes de financiamiento y el papel las instituciones. 
La heroica y mítica vanguardia del 68 , glorificada y anhelada por su rosa shocking -como fuera dicho por Montequín en el debate del Malba- ubicó al margen de las instituciones artísticas sus radicales experiencias estético-políticas (Longoni \& Mestman, 2000). Según la historiadora Andrea Giunta, a principios de 1968 "era evidente que si la vanguardia [argentina] quería seguir siendo un elemento perturbador, si pretendía trastornar el orden de las cosas, no podía ya actuar dentro del marco de las instituciones" (2001, p.1). De todas las experiencias de esa década, Tucumán Arde constituía la obra más renombrada, revisitada, estudiada y exhibida no solo en Argentina sino también en los centros artísticos más legítimos de Europa y Estados Unidos. El ingreso de esta experiencia de la vanguardia radicalizada al canon "se inscribe en un doble proceso de legitimación: aparece como episodio fundante del llamado 'conceptualismo ideológico' y como 'madre' de las aspiraciones de articular arte y política posteriores en Argentina y en la escena internacional (Longoni, 2014, p. 1). Madre que, al parecer, para las nuevas generaciones de activistas resultaba muy difícil desoír.

No obstante, podríamos ubicar un gesto de rebelión ante ese glorioso pasado del arte político argentino que encarna Tucumán Arde, si observamos el cambio que los jóvenes artistas activistas propusieron en torno a los modos de vinculación con la tan temida institución-arte. Desafiando los mandatos de esa pesada herencia, los colectivos de arte activista surgidos desde mediados de los 90 se ubicaron en una nueva posición que no se definía ni adentro ni afuera, o mejor dicho, se reivindicaba en ambos lugares a la vez, tal como concluye el Manifiesto ArteBIENE del grupo Etcétera (2004): "Estar Adentro, Estar Afuera, Etcétera...".

Esa actitud los diferencia, a su vez, de las iniciativas artísticas ligadas al movimiento de derechos humanos en los años 80: el Siluetazo y la silueta de Dalmiro Flores realizada por GASTAR CAPATACO, acciones en el espacio público urbano sumamente potentes políticamente pero ignoradas por el campo artístico durante varios años. Como afirma el investigador Jaime Vindel, el GAC "ha participado del nuevo ímpetu memorístico administrado -y, en ocasiones fiscalizado- por el poder político" (2014, p. 379), como por ejemplo el Parque de la Memoria y la transformación de la ex ESMA (Escuela de Mecánica de la Armada que durante los años de la última dictadura funcionó como un centro clandestino de detención y exterminio).

Aunque en Buenos Aires las nuevas prácticas de arte activista encontraron mayor recepción en las asambleas, marchas y piquetes que en los espacios expositivos del campo artístico, los nuevos grupos no rechazaron a priori la participación institucional como parte de su programa crítico. Un "entrar y salir de la institución" que, al decir del investigador-activista Marcelo Expósito (2006), puede caracterizarse como un continuo en el que la participación institucional no se evita sino que incluso se contempla "sin ser el objetivo central". Una nueva dinámica en la que los artistas realizan la puesta en valor del trabajo artístico tanto al interior de la institución como en la calle, junto a las nuevas formas de protesta social.

Se trata, en suma, de una modalidad distinta acción y relación con las instituciones que plantea tensiones, rupturas y reacomodamientos al interior del campo, pero también nuevos desafíos y preguntas sobre los modos de hacer arte y hacer política en el mundo actual. 


\section{Referencias}

Abal, J. (28 de agosto de 2011). El mercado argentino del arte está movimiento. Suplemento iEco Clarín. Recuperado de http://www.clarin.com/empresas_y_ negocios/mercado-argentino-arte-movimiento 0 544145844.html.

Alonso, R. \& González, V. (2003). Ansia y devoción: Imágenes del presente. Buenos Aires, Argentina: Fundación Proa.

Amigo, R. (2008). 80/90/80. Ramona, 87, 8-14.

Bürger, P. (1987). Teoría de la vanguardia. Buenos Aires, Argentina, Península.

Cerviño, M. (2010). Indicios del cambio de régimen en el campo artístico de Buenos Aires: Los pintores de los 80 frente al arte light. En Jornadas Producción cultural, nuevos saberes e imaginarios en la sociedad argentina contemporánea, a la luz de la Globalización. Buenos Aires, Argentina: Instituto de Investigaciones Gino Germani, Facultad de Ciencias Sociales de la UBA.

Expósito, M. (1 de octubre de 2006). Entrar y salir de la institución: autovalorización y montaje en el arte contemporáneo. Transversal. Recuperado de http:/eipcp.net/ transversal/0407/exposito/es

Giunta, A. (2001). Tucumán ardía. Revista Ñ. Recuperado de http://www.pagina12. com.ar/2001/suple/Libros/01-05/01-05-27/nota4.htm\#111

----(2003). Intervención. Vanguardias Argentinas. Buenos Aires, Argentina, Libros del Rojas.

Gorelik, A. (2005). Preguntas sobre la eficacia: vanguardias, arte y política. Punto de vista, 82, 6-12.

Grupo Etcétera (2004). ArteBiene. En Grupo Etcétera. Recuperado de http:// grupoetcetera.wordpress.com/artebiene/.

----(2007). Etcétera... Etcétera... (cat. exp.). Buenos Aires, Argentina: Centro Cultural Recoleta-Página/12.

Jacoby, R. (2003a). Entrevista realizada por Juan Ignacio Vallejos. En Longoni, Ana (editora), El deseo nace del derrumbe. Roberto Jacoby: Acciones, conceptos, escritos (pp. 386-387). Barcelona, España: Ediciones de La Central - Adriana Hidalgo Editora - Museo Nacional Centro de Arte Reina Sofía.

----(2003b). Arte Rosa Light y Arte Rosa Luxemburgo. Ramona, 33, 70-74.

----(2008). Cuestiones de amor y de muerte. Ramona, 87, 39-45.

Krochmalny, S. (7 de julio de 2010). Tecnologías de la amistad y tecnologías de la confrontación: ¿ni un metro cuadrado de sociabilidad? Planta, 14. Recuperado de http://plantarevista.blogspot.com.ar/2010/07/14.html.

Longoni, A. (2005a). ¿Tucumán sigue ardiendo? Sociedad, 24, 1-11.

-----(2005b). La legitimación del arte político. Brumaria, 9, 61-77.

-----(2007). Encrucijadas del arte activista en la Argentina. Ramona, 74, 31-43.

-(2014). El mito de Tucumán arde. Artelogie, 6, 1-10.

Longoni, A. \& Mestman, M. (2000). Del Di Tella a Tucumán Arde. Buenos Aires, Argentina: El cielo por asalto.

Montequín, E. (2003). Estertores de una estética. Ramona, 31, 34-40.

Ramona (2006), 55, 56-79.

Restany, P. (1995). Arte guarango para la Argentina de Menem. Lápiz, 1, 116. 
Richard, N. (2007). Fracturas de la memoria. Buenos Aires, Argentina, Siglo XXI Editores.

Rubinich, L. (2009). Reinventar el fuego. Apuntes de Investigación del Cecyp, 15, 113-158.

Zukerfeld, F. (2003). Bisagra times. El surmenage de la muerta, 7, 15.

\section{Notas}

1. Tanto el GAC como Etcétera continúan activos hasta el día de hoy (Etcétera bajo el nombre de Internacional Errorista). El TPS, en cambio, se disolvió en el año 2007.

2. Cabe destacar en este punto la intervención de Magdalena Jitrik en el debate, que se desmarcó del tono beligerante sostenido por otros participantes. La artista, que había sido parte del llamado grupo del Rojas y luego de la crisis del 2001 formaba parte del TPS, se reconoció en el cruce de las contradicciones y llamó a reagrupar y desarrollar el potencial creador de la comunidad artística independientemente de los requerimientos institucionales.

3. El recorte temporal 2002-2007 responde al hecho de que a partir del 2007 se registran cambios significativos en relación con la escena artístico-política suscitada desde diciembre de 2001. Algunos de los hechos que se vinculan con este proceso tienen que ver con la segmentación o disolución de los colectivos de arte activista y la consolidación de la política de derechos humanos impulsada por el gobierno de Néstor Kirchner (Longoni, 2007). 